\title{
Międzynarodowa Konferencja Naukowa „Rodzina Miłoszów i inne rody pogranicza litewsko-polskiego", Wilno 8-9 XI 2019 roku. Sprawozdanie
}

International Scientific Conference "The Milosz family and other families from the Lithuanian-Polish border region", Vilnius 8-9 November 2019.

A report

Międzynarodowa Konferencja Naukowa „Rodzina Miłoszów i inne rody pogranicza litewsko-polskiego. Historia, losy, świadectwa literackie", która odbyła się w dniach 8-9 listopada 2019 roku w Wilnie, była trzecią już odsłoną trwającego od 2015 roku projektu naukowego pod nazwą „Bilingwizm w Europie Środkowo-Wschodniej. Literatura, język, kultura"'. Ambicją pomysłodawców projektu jest nowe ujęcie zagadnień bi- i polilingwizmu polegające na

* Anna Janicka - dr hab., prof. UwB; pracuje w Zakładzie Filologicznych Badań Interdyscyplinarnych Uniwersytetu w Białymstoku. Autorka książki Tradycja i zmiana. Literackie modele dziewiętnastowieczności: pozytywizm i ,obrzeża” (Białystok 2015).

1 Poprzednie imprezy: A. Janicka, Międzynarodowa Konferencja Naukowa „Dwujęzyczni pisarze polscy i litewscy. Zagadnienia bilingwizmu w kulturze polskiej i litewskiej. Literatura - kultura - język”. Wilno -Szetejnie, 8-9 października 2015 r., „Bibliotekarz Podlaski” 2016/1, s. 301-305; taż, II Międzynarodowa Konferencja Naukowa „Dwujęzyczni pisarze litewscy i polscy XIX i XX wieku. Perspektywa komparatystyczna. W kregu inspiracji Mickiewicza i Baranauskasa”, Wilno - Onikszty 12-13 października 2017 roku, ,Bibliotekarz Podlaski” 2017/4, s. 361-364; M. Napiórkowski, Międzynarodowa Konferencja Naukowa „Folklor litewski i polski XIX oraz XX wieku. Źródła-literackie przeksztatcenia-interpretacje”, Wilno-Onikszty 23-24 listopada 2018 roku. Sprawozdanie, „Bibliotekarz Podlaski” 2019/2, s. 455-460. 
silnym wpisaniu tego zjawiska w kontekst historyczno-kulturowy środkowoi wschodnioeuropejski, obejmujący tereny dawnej Rzeczypospolitej z jej uwarunkowaniami etnicznymi, językowymi, religijno-społecznymi.

Konferencję w Wilnie wspólnie zorganizowały: Katedra Badań Filologicznych „Wschód - Zachód” z Wydziału Filologicznego Uniwersytetu w Białymstoku, wileńska Akademia Edukacji z Uniwersytetu Witolda Wielkiego w Kownie i Książnica Podlaska im. Łukasza Górnickiego w Białymstoku. Inicjatorami badań byli, tak jak w dwu poprzednich edycjach: dr hab. Andrzej Baranow, prof. UwB (Białystok i VDU Wilno) oraz prof. Jarosław Ławski (UwB, Białystok). Merytoryczną opiekę nad sesją sprawował Komitet Naukowy, któremu przewodniczył prof. Dainius Vaitiekūnas (VDU, Wilno)², zaś przygotowaniami kierował Komitet Organizacyjny ${ }^{3}$. W czasie Konferencji podjęto następujące zagadnienia badawcze:

- Wielokulturowość rodów Wielkiego Księstwa Litewskiego.

- Twórczość Czesława i Oskara Miłoszów w kontekście bilingwizmu, pograniczności, wielokulturowości.

- Dzieje i twórczość pisarzy z terenów WXL, pochodzących z rodzin bii polilingwicznych.

- Język pisarzy pogranicza polsko-litewskiego, polsko-bałtyckiego.

- Litewscy i polscy pisarze dwujęzyczni.

- Pogranicze litewsko-słowiańskie i jego świadectwa w piśmiennictwie polskim i litewskim.

- Ród, rodzina, plemienność, narodowość w literaturach z terenów Wielkiego Księstwa Litewskiego.

2 W skład Komitetu Naukowego weszli ponadto: prof. Marek Bernacki (ATH, Bielsko-Biała); prof. Mieczysław Jackiewicz (UWM, Olsztyn); prof. Žydronė Kolevinskienė (VDU, Wilno); prof. Halina Krukowska (UwB, Białystok); doc. dr Irena Masojć (LEU, Wilno); prof. Małgorzata Mikołajczak (UZ, Zielona Góra); prof. Violetta Wejs-Milewska (UwB, Białystok); prof. dr Sigute Radzevičienė (VDU, Wilno); prof. dr hab. Dariusz Kulesza (UwB, Białystok); dr hab. Anna Szawerna-Dyrszka, prof. UŚ (Katowice); prof. dr hab. Zbigniew Chojnowski (UWM, Olsztyn).

3 W składzie Komitetu Organizacyjnego znaleźli się także: prof. Andrzeja Baranow - Przewodniczacy (VDU, Wilno); prof. Jarosław Ławski - Przewodniczacy (Uniwersytet w Białymstoku); mgr Karolina Bułkowska - UwB, Białystok - Sekretarz; dyr. Jolanta Gadek - Książnica Podlaska im. Ł. Górnickiego w Białymstoku; mgr Kamil K. Pilichiewicz (UwB, Białystok); dr Henryka Sokołowska (VDU, Wilno); doc. dr Barbara Dwilewicz (VDU, Wilno); doc. dr Krystyna Syrnicka (VDU, Wilno); dr hab. Anna Janicka - Wydział Filologiczny Uniwersytetu w Białymstoku; dr Łukasz Zabielski - Książnica Podlaska im. Ł. Górnickiego w Białymstoku - Sekretarz; doc. dr Halina Turkiewicz - VDU, Wilno; mgr Patryk Suchodolski - Książnica Podlaska im. Ł. Górnickiego. 
Sesja odbywała się w pięknym, jesiennym Wilnie. Jej goście zagraniczni zamieszkali w Hotelu „Grata” (ul. Vytenio 9), a obrady odbywały się w nowej siedzibie Akademii Edukacji (ul Ševčenskos 37). Świadectwem gościnności litewskich współorganizatorów pozostanie w naszej pamięci uroczysta kolacja w restauracji „Pan Tadeusz” (ul. Naugarduko 76). Uczestnikom Konferencji raczej sprzyjała trudna o tej porze roku na Litwie do przewidzenia pogoda - można było śmiało zwiedzać miasto. W przedsięwzięciu wzięło udział 37 referentów z Polski (22), Litwy (13) i Ukrainy (2).

Obrady zostały zainicjowany uroczyście w gmachu i auli Akademii Edukacji w piątek 8 listopada 2019 roku o godz. 9.30.

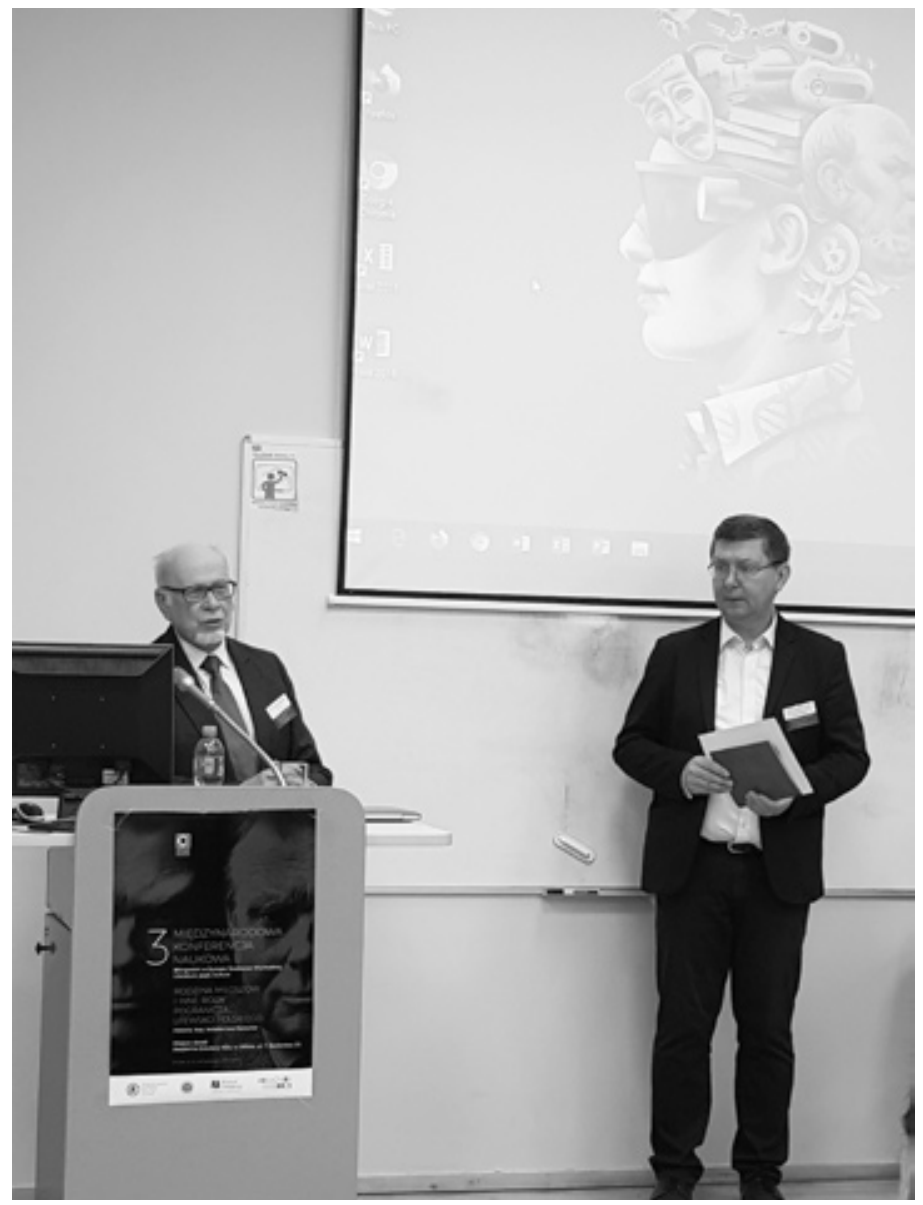

Inauguracja Konferencji w Akademii Edukacji (8 XI 2019). Przemawia prof. Tadeusz Bujnicki (UW, Warszawa), obok prof. Jarosław Ławski (UwB) 
W części uroczystej uczestników projektu powitali prof. Andrzej Baranow, prof. Jarosław Ławski oraz prof. dr Vilija Salienè, kanclerz Akademii Edukacji VDU. Głos zabrała także dyr. Jolanta Gadek, podkreślając zaangażowanie Książnicy Podlaskiej w pracę na rzecz zbliżenia Polaków i Litwinów poprzez kulturę. Prof. Tadeusz Bujnicki (UW, Warszawa) otworzył obrady, powierzając ich prowadzenie w części plenarnej prof. Violetcie Wróblewskiej (UMK, Toruń) oraz prof. Baranowowi. Wystąpili (godz. 10.00 - 12.00) następujący referenci:

- Prof. Krystyna Rutkowska (Uniwersytet Wileński), Językowy obraz dworu na Kowieńszczyźnie.

- Prof. Tadeusz Bujnicki (UW, Warszawa), Polski dwór w Auksztocie Litewskiej. Józef Weyssenhoff i Michat Romer.

- Doc. dr Olga Ciwkacz (Towarzystwo Kultury Polskiej im. Franciszka Karpińskiego, Ukraina), Czestaw Milosz i Stanisław Vincenz - historia przyjaźni i twórczej wspótpracy.

- Dr hab. Anna Szawerna-Dyrszka, prof. UŚ (Katowice), Watki autobioraficzne w twórczości Miłosza.

- Dr Łukasz Zabielski (Książnica Podlaska w Białymstoku), ,, Ród” $i$,,rodzina" w twórczości Zygmunta Glogera ${ }^{4}$.

Po krótkiej dyskusji i przerwie kawowej przystąpiono do obrad w trzech sekcjach tematycznych: I: Literaturoznawstwo; II: Kultura i język; III. Konteksty kulturowo- historyczne ${ }^{5}$. Około godz. 19.00 uczestnicy przeszli do nieodległej restauracji „Pan Tadeusz” na obiad, gdzie też wieczorem około 19.00 spotkali się na wspólnej biesiadzie.

Inny charakter miał drugi dzień obrad, które przeniosły się do Muzeum Adama Mickiewicza (ul. Bernardinų 11).

4 Uczestnicy Konferencji reprezentowali różne ośrodki litewskie (VDU w Kownie, Uniwersytet Wileński), ukraińskie (Odessa, Ivano-Frankivsk) i polskie (Poznań, Gdańsk, Toruń, Katowice, Warszawa, Suwałki, Białystok, Łódź, Częstochowa).

5 Obrady w Sekcjach prowadzili: (I) prof. Hanna Ratuszna (UMK, Toruń), prof. Anna Szawerna-Dyrszka (UŚ, Katowice); (II) doc. dr Olga Ciwkacz (Ivano-Frankivsk, Ukraina), dr Łukasz Zabielski (Książnica Podlaska), prof. Anna Nosek (UwB, Białystok), prof. Maciej Szargot (UŁ, Łódź); (III) prof. Tadeusz Bujnicki (UW, Warszawa), prof. Krystyna Rutkowska (Uniwersytet Wileński), dr Monika Pokorska-Iwaniuk (UAM, Poznań). 


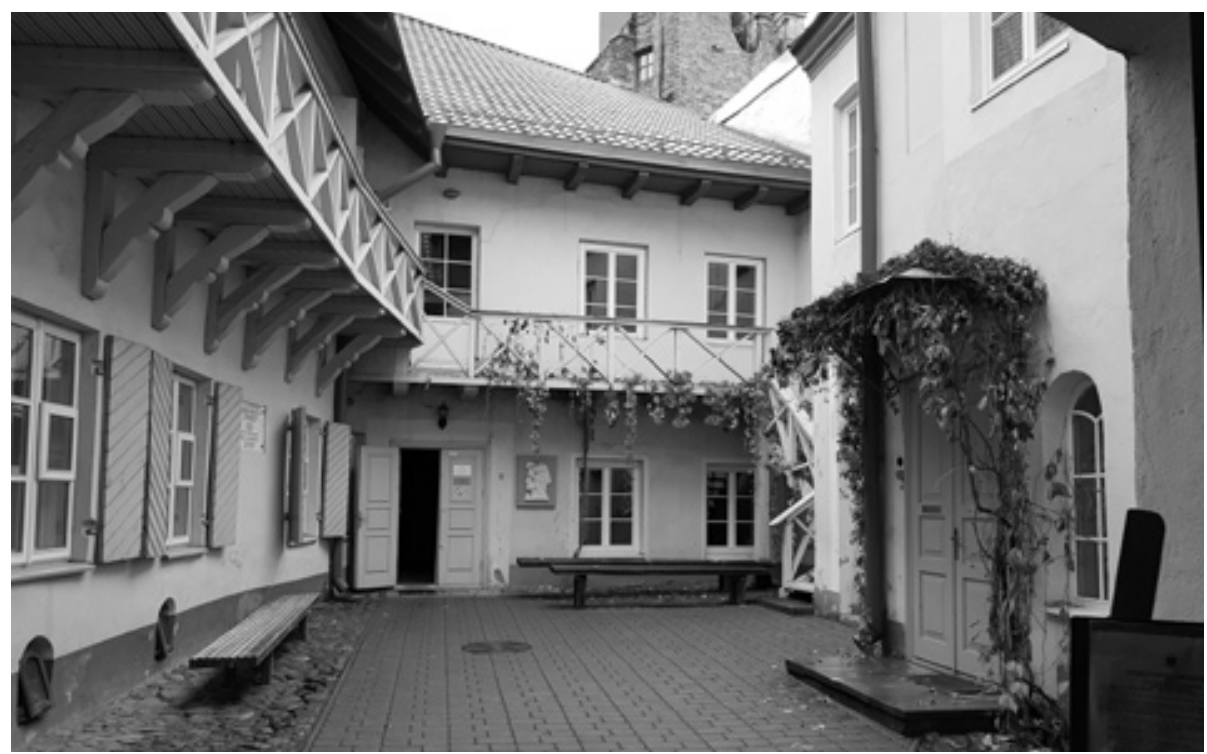

Muzeum Adama Mickiewicza w Wilnie, u. Bernardyńska 11

W salach muzeum przywitał uczestników dyr. Rimantas Šalna, znany popularyzator wiedzy o polsko-litewskiej kooperacji i zarazem poeta ${ }^{6}$. Obradom przewodniczył prof. Zbigniew Kaźmierczyk (UG, Gdańsk). Wysłuchano następujących wystąpień:

- Dr Marcin Niemojewski (Uniwersytet Warszawski), Rodzina Zawadzkich-drukarze Obojga Narodów.

- Dr Monika Pokorska-Iwaniuk (UAM, Poznań), Adaptacje „,Grażyny” Adama Mickiewicza w literaturze i sztuce litewskiej.

Po dyskusji i poczęstunku badacze udali się z ulicy Bernardyńskiej na pieszą wędrówkę po Wilnie, którą zaproponował dr Józef Szostakowski ${ }^{7}$, znany w mieście regionalista, specjalizujący się w wileńskich polonikach, pracujący w Muzeum Władysława Syrokomli w Borejkowszczyźnie ${ }^{8}$. Uczestnicy projek-

6 Zob. R. Šalna, Vilnietiški apurastymai / Impresje wileńskie, Vilnius 2002; tenże, Adam Mickiewicz w Wilnie. Adam Mickiewicz a kobiety, Wilno 2012.

7 Napisał on m. in. prace: Czerwone gile, Warszawa 1994; Wilno i okolice. Przewodnik literacki, Wilno 2012; Śladami pamięci, Wilno 2012.

8 W Muzeum Baranauskasa w Oniksztach obradowała inna polsko-litewska Konferencja: „Folklor litewski i polski XIX oraz XX wieku. Źródła - literackie przekształcenia - interpretacje”, Wilno - Onikszty 23-24 XI 2018 r. 
tu dotarli „wileńskimi śladami nie tylko Czesława Miłosza” do miejsc związanych z życiem tak licznych sławnych wilnian-Polaków: od Mickiewicza i Słowackiego po Miłosza. W godzinach popołudniowych Konferencja zakończyła się tuż obok gmachu Uniwersytetu Wileńskiego, w miejscu symbolicznym dla wszystkich jej uczestników.

Konferencja o „Rodzinie Miłoszów i innych rodach pogranicza litewskopolskiego" ${ }^{\text {W }}$ sposób nieprzewidziany zamknęła na całe dwa lata współpracę międzynarodową Katedry Badań Filologicznych „Wschód - Zachód” i całego Wydziału Filologicznego Uniwersytetu. W okresie pandemii koronawirusa (2020-2021) współpraca ta albo zamarła, albo przeniosła się do Internetu. W tym kontekście wileńska Konferencja pozostaje nie tylko udaną imprezą naukową, lecz także jedynym w swoim rodzaju wspomnieniem świata, którego już nie ma.

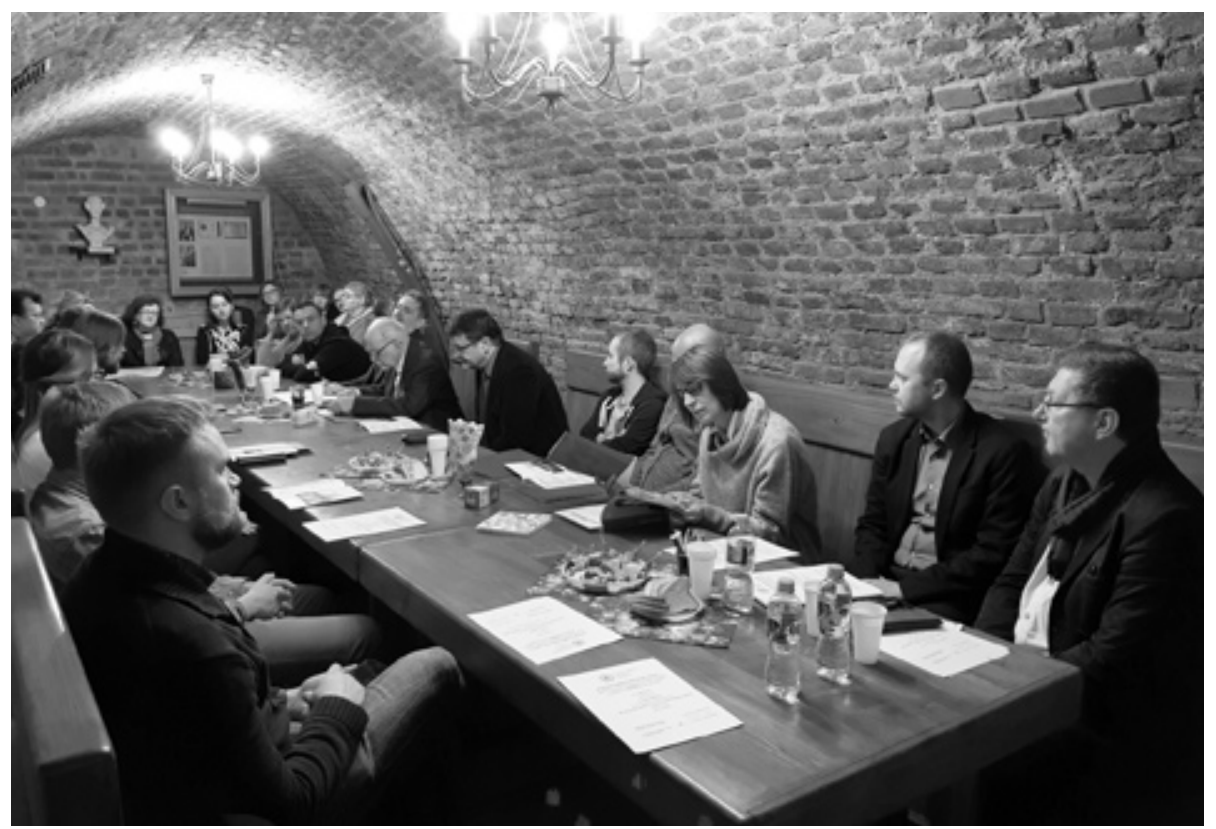

Obrady Konferencji w Muzeum Adama Mickiewicza (9 IX 2019)

9 Zob. drukowany program sesji: 3 Międzynarodowa Konferencja Naukowa „Bilingwizm w Europie Środkowo-Wschodniej. Literatura, język, kultura": Rodzina Miłoszów i inne rody pogranicza litewsko-polskiego. Historia, losy, świadectwa literackie, Wilno 8-9 listopada 2019 roku. Program, opr. A. Baranow, P. Suchodolski, tekst D. Kukiełko, J. Ławski, opr. graf. H. Pilcicki, druk: Prymat. Mariusz Śliwowski, Białystok 2019, ss. 16. 


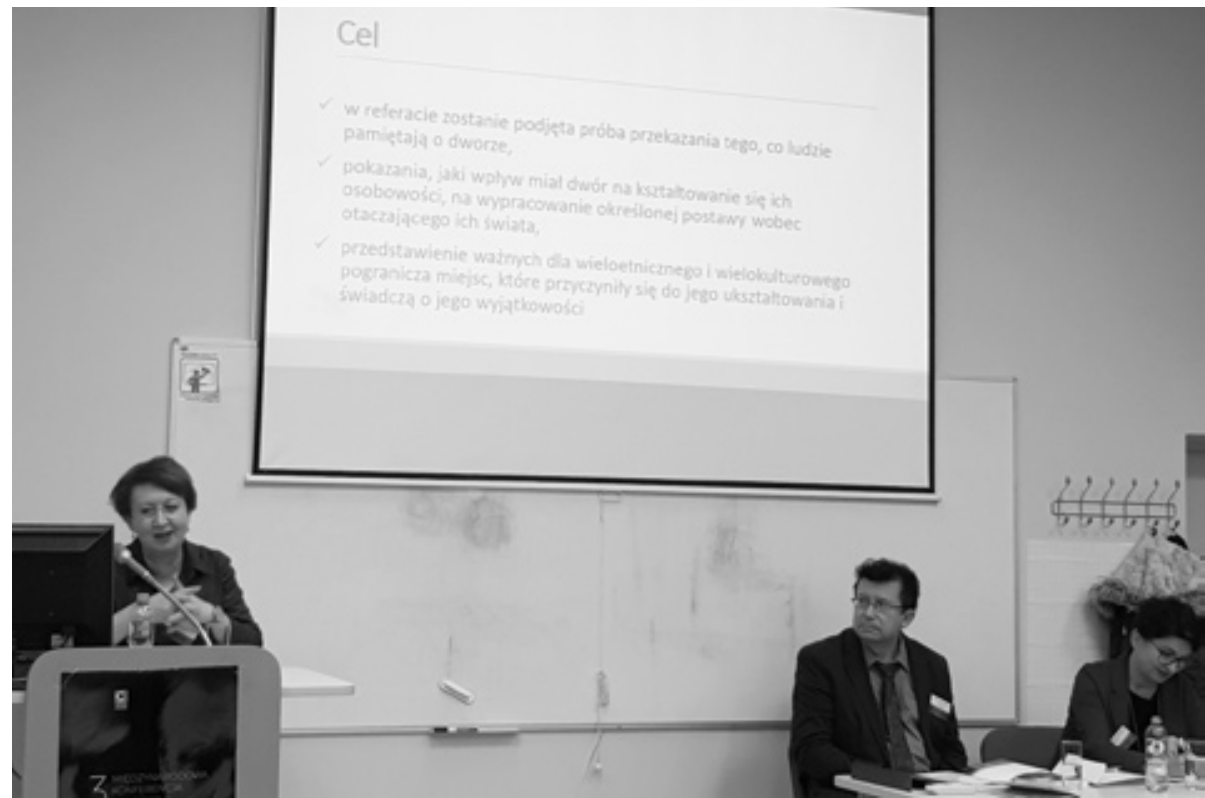

Obrady plenarne. Akademia Edukacji (8 XI 2019). Wystąpienie prof. Krystyny Rutkowskiej (Uniwersytet Wileński). Za stołem: prof. Violetta Wróblewska (UMK, Toruń), prof. Andrzej Baranow (Akademia Edukacji VDU)

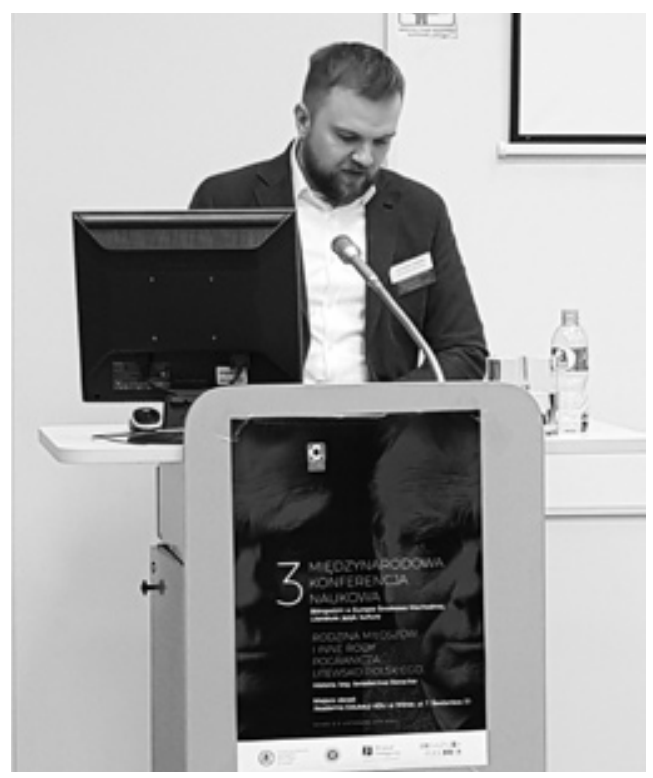

Obrady plenarne. Akademia Edukacji (8 XI 2019).

Wystąpienie dra Łukasza Zabielskiego (Książnica Podlaska) 


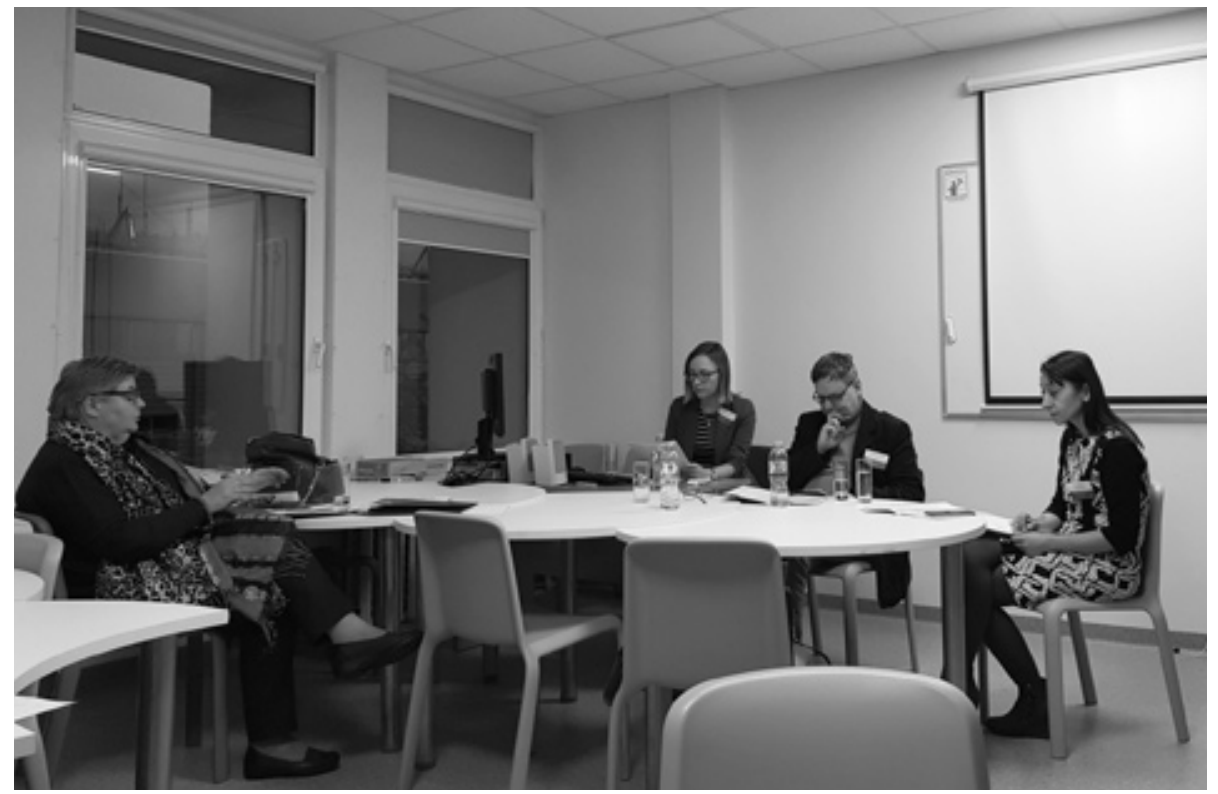

Obrady Sekcji II. Od prawej: prof. Anna Nosek (UwB, Białystok), prof. Maciej Szargot (UŁ, Łódź), mgr Joanna Godlewska (UwB, Białystok), prof. Barbara Szargot (UJD, Częstochowa) 